\title{
A evasão nos cursos de graduação em uma instituição de ensino superior privada
}

\author{
Rosangela Fritsch \\ Cleonice Silveira da Rocha \\ Ricardo Ferreira Vitelli \\ Universidade do Vale do Rio dos Sinos
}

\section{Resumo}

Este artigo trata da evasão na educação superior tendo como objetivo identificar e avaliar variáveis que estariam interferindo na evasão para agir de forma proativa e preventiva junto a esse público.A pesquisa desenvolvida é de abordagem quantitativa, com uma análise multivariada e regressão logística. Como resultado, pôde-se identificar variáveis que impactam na evasão, delinear um perfil de aluno com propensão à evasão e construir um modelo estatístico que pudesse predizer, com a máxima exatidão possível, a probabilidade de um aluno se evadir. As variáveis mais significativas estão relacionadas a fatores sociais, econômicos, de desempenho acadêmico e de escolha profissional.

81 Palavras-chave: Evasão escolar. Educação superior. Gestão universitária.

\section{The evasion in undergraduate courses in a private institution of higher education}

\section{Abstract}

The focus of the present paper is on the tax evasion of a given higher education institution. It seeks identify and to evaluate the variables influencing this phenomenon in order to act actively and preventively towards these students. It is a quantitative research where we performed a multivariate analysis and logistic regression. As a result, we could identify the variables influencing on the evasion of these students, delineate the profile of a student prone to evade and build a statistical model that can predict, with the highest level of accuracy, the probability of a student to evade. The most significant variables are related to social, economic, academic achievement and career choice.

Keywords: School evasion. Higher education. University management. 


\section{Elevasion en cursos universitarios en una institución privada de educación superior}

\section{Resumen}

Este artículo se ocupa de la evasión en la educación superior con el objetivo de identificar y evaluar las variables que estaban interfiriendo con la evasión de actuar de forma proactiva y preventivamente con esta audiencia. La investigación desarrollada es un enfoque cuantitativo con un análisis de regresión multivariante y logístico. Como resultado, fue posible identificar las variables que la evasión de impacto, delinear un perfil de estudiante propenso a la evasión y construir un modelo estadístico que podría predecir, con la mayor exactitud posible, la probabilidad de que un estudiante de evadir. Las variables más importantes se relacionan con el desempeño social, económico, académico y profesional de la escuela.

Palabras clave: Abandono de los estudiantes. Educación superior. Gestión universitaria.

\section{Introdução}

A evasão escolar está relacionada à perda de estudantes que iniciam, mas não concluem seus cursos. É um fenômeno complexo, associado à não concretização de expectativas e reflexo de múltiplas causas que precisam ser compreendidas no contexto socioeconômico, político e cultural, no sistema educacional e nas instituições de ensino. A evasão escolar significa desistência por qualquer motivo, exceto conclusão ou diplomação, e é caracterizada por ser um processo de exclusão determinado por fatores e variáveis internas e externas às instituições de ensino.

No campo da gestão educacional, a evasão é um indicador de fluxo escolar que sinaliza, de alguma forma, o desempenho dos sistemas de ensino. Este artigo aborda a evasão em uma Instituição de Ensino Superior privada, porém se entende que a permanência na educação superior implica a trajetória escolar dos estudantes na educação básica.

$O$ acesso e a permanência de estudantes no sistema aparecem em tonalidades diferentes nos documentos oficiais. Na Lei de Diretrizes e Bases da Educação (LDB), o art. $3^{\circ}$ descreve que "[...] o ensino será ministrado com base no princípio da igualdade de condições para o acesso e permanência na escola" (BRASIL, 1996, p. 12). 
A Educação Superior no Plano Nacional de Educação (PNE), período de 2014-2024, tem, entre suas metas, a de elevar a taxa bruta de matrícula na educação superior para 50\%, e a taxa líquida para 33\% da população de 18 a 24 anos, assegurada a qualidade da oferta e expansão para, pelo menos, 40\% das novas matrículas, no segmento público, estabelecendo 21 estratégias (meta 12); e a meta de elevar a qualidade da educação superior e ampliar a proporção de mestres e doutores do corpo docente em efetivo exercício no conjunto do sistema de educação superior para $75 \%$, sendo, do total, no mínimo, 35\% doutores, estabelecendo 9 estratégias para seu cumprimento (meta 13) (BRASIL, 2014).

Analisando as metas e as estratégias, percebe-se uma prevalência da preocupação com acesso e com sistemas de avaliação do ensino superior. A democratização do acesso associa-se à necessidade de preocupação com a manutenção dos alunos no sistema, até a sua diplomação.

$\bigcirc$ Estado tem desenvolvido políticas educacionais para a inclusão de alunos com poucas possibilidades de acesso às instituições privadas de educação superior. As estratégias, definidas no PNE (2014-2024), indicam a continuidade dos programas: o Programa Universidade para Todos (ProUni),

83 que busca conceder bolsas de estudo integrais e parciais em cursos de graduação e sequenciais de formação específica; e o Fundo de Financiamento do Estudante do Ensino Superior (Fies), que oferece isenção ou pagamento de alguns tributos àquelas instituições de ensino que aderem aos programas fortalecendo, assim, o sistema privado no ensino superior (BRASIL, 2014).

Segundo o Censo da Educação Superior de 2012 do Ministério da Educação (MEC), na graduação, existem 2416 instituições com oferta dessa modalidade, sendo 2112 privadas. As Instituições de Ensino Superior (IES) privadas têm uma participação de $73 \%$ no total de matrículas de graduação. Dias Sobrinho (2005; 2008; 2010), Dourado (2002; 201 1), Mancebo (2008), Peroni (2003, 2013), entre outros, têm analisado o cenário de educação superior no Brasil e a relação público/privado acentuando a preocupação com a privatização e com a qualidade da educação.

De qualquer forma, a possibilidade de mais acesso, por si só, é necessária, mas não suficiente para a manutenção dos alunos no sistema até a sua diplomação. A evasão no ensino superior causa perda para o sistema educacional, para os atores envolvidos no processo e para as instituições de ensino. 
ensino superior brasileiro vem apresentando elevados índices de evasão em seus cursos de graduação. Tomando os dados dos últimos censos- 2010, 2011 e 2012 -, o número de matriculados foi de6.407.733, 6.765.540 e 7.058.084, respectivamente. Por sua vez, o número de concluintes foi de 980.662, 1.022.711 e 1.056.069 e o número de ingressantes foi de 2. $196.822,2.359 .409$ e 2.756 .773 .

O MEC conceitua evasão como sendo a saída definitiva do curso de origem sem conclusão, ou a diferença entre ingressantes e concluintes, após uma geração completa. Quando faz referência a uma geração completa, o Ministério assume a ideia de que o tempo entre ingresso e conclusão é definido como o prazo máximo de conclusão do curso. Tendo essa definição como referência, o ensino superior brasileiro amarga uma evasão de 16,09\%, $18,81 \%$ e 25, $11 \%$ respectivamente. Mesmo que a oferta esteja em ascensão, é discrepante a relação entre matriculados, ingressantes e concluintes.

Esse fenômeno é percebido tanto em instituições púbicas de ensino quanto em instituições privadas, e buscar compreender suas causas tem sido objeto de muitos trabalhos e pesquisas na área educacional. A revisão de literatura efetivada na Biblioteca Digital de Teses e Dissertações do Instituto Brasileiro de Ciência e Tecnologia (IBICT) e Portal da Coordenação de Aperfeiçoamento de Pessoal de Nível Superior (Capes),catalogou 120 pesquisas, no período 2000 a 2014 , sendo 9 teses, 43 dissertações e 68 artigos.

A maioria dessas pesquisas teve, como objeto de estudo, a identificação e ou compreensão dos motivos da evasão. Contribuíram, especialmente, para este estudo os seguintes trabalhos: Adachi (2009); Amaral (2013); Andriola (2009); Baggi (2010); Biazus (2004); Bardagi (2007); Fialho (2008); Martins (2007); Matias (2003); Palácio (2012); Pereira (2003); Pereira Júnior (2012); Silva Filho, Motejunas, Hipólito, Melo Lobo (2007); Silva (2009); Teixeira (2006); Veloso e Almeida (2002).

Entre as varáveis encontradas nesses estudos que interferem na evasão, destacam-se: falta de motivação de alunos e professores; problemas pessoais e socioeconômicos; oferta de novas opções de curso e/ou instituições; insatisfação com o curso e / ou instituição; problemas de aprendizagem relacionados com metodologias de ensino e avaliação; aspectos inadequados relacionados à maneira como os professores falam dos cursos e a inadequação das salas de aula ao ensino ministrado; dedicação a outro curso ou preparação para outro vestibular; restrições do mercado de trabalho; incerteza sobre a escolha 
profissional; a inexistência de uma integração entre a universidade e as empresas no que concerne aos estágios supervisionados; o desconhecimento prévio do curso por parte dos alunos; a não concretização das expectativas individuais dos alunos e a "pressão" exercida pela família sobre a escolha do curso; repetências continuadas nas disciplinas; nível de estudo anterior à matrícula; desemprego; dificuldade de conciliar emprego e estudo.

As pesquisas apontam para um conjunto de indicadores cuja influência contribui para a concretização da evasão, porém, de naturezas diferenciadas, em função das escolhas de recorte, das metodologias, das realidades estudadas e do fato de que é um fenômeno complexo que tem múltiplas causas.

A Instituição de Ensino Superior privada, campo empírico deste estudo, preocupada com a evasão, vem realizando estudos quantitativos e qualitativos, desde 2008 trabalhando a evasão a partir de uma perspectiva de gestão: diagnóstico, monitoramento, execução e avaliação de ações.

$\bigcirc$ presente estudo avalia e identifica variáveis que estariam interferindo na evasão para agir de forma proativa e preventiva junto a esse público, a partir de um conjunto de 34 informações disponibilizadas em banco de dados sobre os alunos. Entre seus objetivos, também, está o de validar variáveis identificadas e perfil de aluno evadido em estudo de mesma natureza, efetivado em 2008. Além disso, tem, igualmente, a intenção de conhecer as possiveis interações existentes entre duas ou mais variáveis e como elas aumentam ou diminuem a chance de um aluno se evadir. Outro aspecto que merece registro é a construção de um modelo estatístico que pudesse predizer, com a máxima exatidão possível, a probabilidade de um aluno se evadir, a partir de um determinado conjunto de variáveis.

Por fim, foi relevante estabelecer um paralelo com as informações pesquisadas no estudo anterior, visando identificar possíveis alterações presentes nas análises dos estudos realizados em 2008 e 2011 . Este trabalho é constituído de quatro partes: uma introdução,uma descrição da metodologia empregada, os resultados atingidos e as conclusões.

\section{Metodologia do estudo}

No presente estudo, foi desenvolvida uma pesquisa de abordagem quantitativa, utilizando um coorte longitudinal. Um estudo de coorte, segundo 
Malhotra (2001), acontece quando se estuda um grupo de pesquisados que experimentam o mesmo evento (matrícula no semestre) no mesmo intervalo de tempo. Um estudo de coorte consiste numa série de levantamentos realizados em intervalos de tempo apropriados, em que o corte serve como uma unidade básica de análise.

No estudo em questão, o tempo de corte foi de 2006-201 1, pois seria um período de tempo suficiente para que os alunos tivessem concluído seu curso e foi o mesmo tempo de corte da pesquisa realizada em 2008, que foi 2003-2008.

Com relação à coleta dos dados, a opção foi de um estudo com busca em banco de dados da instituição de forma censitária. Ao longo do percurso da pesquisa, em função de algumas variáveis coletadas não terem resposta, a modelagem dos dados desconsiderou os indivíduos que não possuíam resposta a alguma variável. Dessa forma, a análise dos dados passou a ser amostral, com a eliminação de alguns indivíduos.

Neste estudo,foram utilizados dois tipos de análises de dados: a bivariada e a multivariada, com a aplicação de Regressão Logística tendo como suposição os resultados do estudo de 2008, concebendo a evasão a partir da conjunção de um conjunto de fatores e variáveis. Na aplicação, realizada em 2011 , a análise univariada não foi utilizada. A opção por essa proposição se fundamenta no fato de que o estudo realizado, em 2008, era de natureza exploratória e contava com pouca informação disponível sobre o foco em estudo. Em 2011 , já havia mais subsídios para a análise dos dados.

A análise bivariada, realizada nas duas aplicações, buscou conhecer a relação existente entre duas variáveis, especificamente entre a variável resposta (evadido) e as demais variáveis que constam do modelo inicial. Quando é necessário entender o comportamento de uma variável a partir de várias variáveis (mais de duas), o processo de análise é de natureza multivariada, que, neste caso, foi desenvolvido por meio da análise de regressão logística. As variáveis identificadas como possíveis explicativas do modelo de evasão foram separadas por blocos em função de possíveis similaridades entre si. Após essa etapa, foram feitas análises bivariadas tentando identificar as relações individuais existentes entre cada variável pesquisada e a condição de aluno evadido ou não. 
Em 201 1, na primeira etapa, foi feita uma Análise Multivariada, por meio da qual observa-se o conjunto de variáveis que pode interferir no fenômeno da evasão não apenas de forma individual, mas também integrada, identificando possíveis interações entre as variáveis. Foram adicionadas algumas variáveis relacionadas com o perfil do evadido, presentes no questionário preenchido pelos alunos, por ocasião da inscrição no vestibular.

A Análise Multivariada é um processo em que se estabelece uma combinação linear de variáveis com pesos empiricamente determinados. As variáveis são especificadas pelo pesquisador, sendo os pesos determinados pela técnica utilizada, para se analisar os resultados da coleta das respostas das variáveis. No processo de Análise Multivariada, a variável definida como resposta (dependente) passa a ser uma combinação linear das demais variáveis (independentes). A escolha de uma técnica multivariada depende do nível de mensuração das variáveis.

No caso deste objeto de estudo, a variável resposta da pesquisa é a evasão, mensurada da seguinte forma: o aluno se evade ou o aluno não se evade. Além de ser um nível de mensuração nominal, é dicotômico sendo, portanto, uma variável que se enquadra na possibilidade de uso de uma análise 87 discriminante múltipla.

Segundo Hair, Anderson, Tatham e Black (2005), a Análise Discriminante Múltipla ou Multiple Discriminant Analysis (MDA) é a técnica multivariada adequada quando a variável dependente é dicotômica. Essa análise é aplicável nas situações em que a amostra total pode ser dividida em grupos baseados numa variável dependente, e seu objetivo é entender diferenças entre os perfis dos grupos; determinar quais variáveis independentes explicam o máximo de diferenças nos perfis e estabelecer procedimentos para classificar indivíduos em grupos com base em seus escores. Uma alternativa para a Análise Discriminante é a Análise de Regressão Logística que apresenta uma gama maior de diagnóstico dos resultados.

Segundo Corrar, Paulo e Dias Filho (2007), a Regressão Logística estima os parâmetros com o apoio do método de máxima verossimilhança e não pelo método dos mínimos quadrados, usado na Análise Discriminante. Com a máxima verossimilhança, buscam-se coeficientes que possam estimar a maior probabilidade possível de um evento ocorrer ou de certa característica se fazer presente. Esse fato é importante, pois vem ao encontro do objetivo deste 
estudo, que é a caracterização do aluno evadido .Por essas razões justificou-se o uso da Regressão Logística em detrimento da Análise Discriminante.

Outro aspecto crucial a ser observado é quanto ao fato de que a utilização da análise de regressão logística necessita de uma amostra significativa. Corrar, Paulo e Dias Filho (2007) indicam que são convenientes 30 casos por variável independente colocada no modelo inicial. Essa restrição é plenamente atendida no estudo em questão, mesmo com a exigência de 30 casos. A partir da definição da opção pela Regressão Logística, alguns passos precisam ser estabelecidos para a sua aplicação. Inicialmente, a decisão pela variável a ser definida como a variável resposta do modelo, no presente estudo, é a evasão.

A segunda etapa consiste em especificar as variáveis que deverão estar no modelo inicial. A opção pelas variáveis a serem incluídas no modelo foram: o julgamento de sua pertinência por parte do pesquisador e a limitação das informações contidas em banco de dados.

A terceira etapa é a criação de variáveis Dummy para as variáveis nominais. Para Hill, Griffiths e Judge (1999), as variáveis dummies, também designadas como variáveis binárias, são variáveis explicativas que podem tomar um de dois valores, 0 ou 1. Como no presente estudo existem variáveis com essas características, o uso desse tipo de recurso passa a ser fundamental.

A quarta etapa do estudo consiste em escolher um meio de constituição do modelo logístico. Assim, a opção foi pela utilização de um pacote estatístico utilizado para o tratamento dos dados da pesquisa. Esse software estabelece a forma de chegar até a equação do modelo de regressão. Para a utilização da Regressão Logística, é necessário definir um método de avaliação do modelo: o método escolhido foi o stepwise (passo a passo).

Nesse método, as variáveis são introduzidas no modelo uma a uma. Após a inclusão das variáveis, o modelo é avaliado no sentido de verificar se melhora sua capacidade preditiva e, passo a passo, são incluídas e excluídas novas variáveis, até que se encontre uma combinação ótima de variáveis. Para Hair, Anderson, Tatham e Black (2005), esse método permite que o pesquisador examine a contribuição de cada variável independente para a melhoria do modelo de regressão. Cada variável é considerada para inclusão antes do desenvolvimento da equação. 


\section{Resultados}

Nesta etapa, são revelados os resultados do estudo, apresentando a análise bivariada dos dados de forma descritiva; a avaliação da qualidade de ajuste da regressão logística; o modelo final da Regressão Logística adotado; um exemplo de previsão utilizando o modelo de regressão logística; algumas considerações sobre os resultados da análise multivariada; e uma comparação dos resultados encontrados nos estudos realizados em 2008 e 2011.

O conceito de evasão depende da granularidade e da temporalidade da informação a ser pesquisada. Dessa forma, a evasão pode ser mensurada a partir da disciplina, do curso, da instituição ou do sistema educacional. A instituição pesquisada designa um discente como sendo evadido do curso quando está há, pelo menos, seis semestres consecutivos sem matrícula (temporalidade), constituindo então na perda da vaga obtida. Essa foi a definição adotada para caracterizar a evasão na população pesquisada.

Ao final do estudo de 2008, conforme consta na Figura 1, os principais fatores que interferem na evasão estão relacionados ao tempo do aluno no curso, desempenho acadêmico, área do curso, indefinição da escolha

89 profissional e condições financeira. Observa-se que grande parte da evasão acontece no primeiro semestre e, até o terceiro semestre, os índices de evasão são mais altos, estabilizando-se após esse período. Quanto ao desempenho acadêmico: muitas reprovações e médias baixas também se mostraram significativas. A área de conhecimento onde o curso está inserido também demonstra uma maior ou menor propensão à evasão. Por fim, a inadimplência e a matrícula em poucas atividades acadêmicas durante os semestres também se revelam como indicador de um potencial aluno evadido. 


\section{Figura 1}

Principais variáveis que interferem na evasão institucional da Universidade em 2008

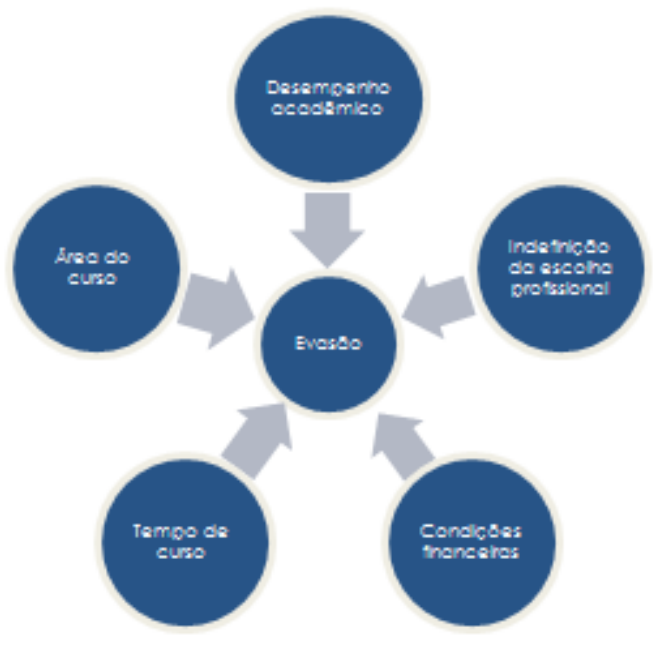

Fonte| Estudo realizado pelos autores em 2008

O estudo de 2011 mostrou que, dos 5.324 alunos que ingressaram em 2006, após cinco anos, 56,67\% já se evadiram da instituição. Segmentando os resultados por área, é possivel perceber que a área de Ciências Humanas foi responsável pela maior participação relativa na evasão (61,09\%). Entre todas as áreas pesquisadas, a de menor taxa de evasão ocorreu na área de Ciências Jurídicas $(50,83 \%)$, ainda que seja alta. Considerando esses resultados e os obtidos no levantamento realizado com os ingressantes em 2003, percebe-se uma tendência de crescimento da evasão, uma vez que o resultado de 2003 apontava para um percentual de 53,79\% lem igual tamanho de corte temporal) e, em 2006, atingiu 56,67\%. Entre as áreas de conhecimento, as de Ciências Humanas, Econômicas e Exatas e Tecnológicas são as que apresentam taxa de evasão superior à institucional, ficando as demais áreas abaixo (Ciências Jurídicas, Ciências da Comunicação e Ciências da Saúde).

A evasão acontece com maior intensidade entre estudantes que ingressam com idade mais elevada. Dois fatores indicam este fato: a média de idade 
dos alunos evadidos é de aproximadamente 25 anos; e a dos não evadidos, de 22 anos. Além disso, os percentuais de evadidos são maiores entre os estudantes mais velhos, comparativamente aos que não se evadem. Esses dados se intensificam entre alunos com idade de ingresso superior a 30 anos de idade. Aglutinando os resultados por faixas etárias, verifica-se que a quantidade de ingressantes com idade de 17 a 20 anos é de 2.289; nesse grupo, a taxa de evasão é de, aproximadamente,46\%. Em compensação, a quantidade de ingressantes com idade superior a 30anos é de 690 e a taxa de evasão é de, aproximadamente, 72\%. Considerando os ingressantes acima de 50 anos a evasão atinge quase 100\%.

Os resultados da variável estado civil indicam que os estudantes solteiros são os que apresentam menor percentual de evasão $(55,81 \%)$. Considerando que a evasão entre os ingressantes mais jovens é menor e a condição civil solteiro ser mais representativa, é possível identificar esse resultado mais explicado pela idade do que pelo estado civil.

A evasão, percebida por meio de indicadores de desempenho no vestibular, demonstra que existe uma relação inversamente proporcional entre esse desempenho e a taxa de evasão, ou seja, alunos com menores médias de 91 desempenho no vestibular tendem a apresentar maiores taxas de evasão escolar.Esse público foi evidenciado no estudo realizado, em 2008, com potencial de evasão pela dificuldade de acompanhamento das exigências dos cursos superiores e indecisão em relação à escolha do curso. Entre aqueles que ingressam com média inferior a 5, a taxa de evasão é de, aproximadamente, $65 \%$.

A evasão para cada uma das formas de ingresso revela que a menor taxa de evasão acontece entre os alunos que ingressam em seus cursos utilizando a bolsa ProUni (26,0 1\%) ou por paralelo interno - matrícula em 2 cursos $(30,56 \%)$. Essas duas formas de ingresso apresentam resultados menores de evasão do que os ingressantes por outras formas. Por outro lado, os maiores percentuais de evasão acontecem entre os estudantes que ingressaram por readmissão $(75,82 \%)$, processo seletivo alternativo $(79,58 \%)$ ou portadores de diploma (82,96\%). Novamente, a variável idade pode estar subjacente a esse resultado, visto que é provável que esses estudantes tenham mais idade. Por outro lado, podem ser alunos com mais tempo entre a conclusão do ensino médio e a inclusão no ensino superior; terem realizado o ensino médio pelo programa de Educação de Jovens e Adultos (EJA), formando-se com menos preparo para ingresso no ensino superior. 
É interessante observar que a quantidade de ingressantes por transferência interna é bastante expressiva, porém a outra possibilidade de curso acaba não se concretizando, uma vez que a taxa de evasão entre esse público é de 53,65\%. São alunos indecisos sobre a sua escolha e mesmo uma segunda possibilidade acaba não se concretizando; dessa forma, ao acompanhar os alunos com muitas transferências, é possível se ter um trabalho de aconselhamento mais direto, ajudando nessa decisão.

estudo indicou um perfil de discente com algumas características comuns. Quanto mais aprovação o aluno apresenta ao longo de sua trajetória no curso, menor tende a ser seu percentual de evasão. E importante destacar que, dos 601 alunos que não obtiveram nenhuma aprovação no período lalguns se evadiram já nos semestres iniciais, quando a evasão é mais acentuada), 92, 18\% acabaram por se evadir da Universidade.

percentual de atividades reprovadas e a relação da taxa de evasão são diretas, ou seja, à medida que aumenta o percentual de atividades reprovadas, aumenta a taxa de evasão. Considerando esses resultados junto à média de ingresso no vestibular, cabe destacar que a instituição deve ter uma preocupação com esse perfil de aluno, em função da necessidade de ações específicas para oferecer condições mínimas aos estudantes durante a sua trajetória no curso, principalmente nos primeiros semestres de ingresso.

Com relação aos percentuais de atividades canceladas, existe uma relação diretamente proporcional entre essa variável e a taxa de evasão. Quanto maior o percentual de atividades canceladas durante a sua trajetória no curso, maior tende a ser a probabilidade de o aluno se evadir. Da mesma forma, observa-se esse fenômeno com relação à proporção de atividades em que o aluno fica sem frequência, ao final do semestre,e à proporção de desistência de atividades acadêmicas no período. Essas duas últimas variáveis podem estar relacionadas à dificuldade de acompanhamento das atividades acadêmicas por falta de conhecimento, problemas pessoais ou incerteza sobre a escolha.

Por outro lado, o percentual de créditos nas disciplinas já concluídos do curso demonstra o avanço do aluno dentro do currículo. Sendo assim, os percentuais de evasão se acentuam mais no início do curso: quanto mais o aluno avança no curso, menor tende a ser sua chance de se evadir. No estudo realizado em 2008 e do acompanhamento dos indicadores de evasão, esse fato já tinha sido levantado. 
Durante a trajetória dos estudantes em sua vida acadêmica, eles, eventualmente, ficam algum semestre sem realizar a sua matrícula. Considerando que, em algum momento dessa trajetória, ele tenha estado um semestre sem matrícula, pode-se perceber que, à medida que aumentam os momentos em que esse fato acontece, aumenta a chance de o aluno se tornar um evadido da instituição. Mais uma vez, o processo de evasão vai sendo construído a partir de indicativos que sinalizam potenciais alunos evadidos possíveis de ser monitorados pela instituição universitária. Em alguns casos, com muitos semestres sem matrícula no período, a evasão não se caracterizou, pois os alunos estavam matriculados no momento da extração dos dados, principalmente nos casos em que há retorno do aluno, após um longo período sem matrícula.

A média de desempenho dos estudantes nas atividades acadêmicas revela que, da mesma forma que a média do ingressante, quanto mais baixa a média do aluno, maior a propensão de ele se evadir da Universidade. Outra variável importante a ser considerada é a média de atividades acadêmicas matriculadas no semestre. Esse dado revela que, da mesma forma que a média do ingressante, quanto mais baixa a média de créditos matriculados do aluno, maior a propensão de se evadir da instituição.

93 As variáveis de caráter financeiro, que incluem também os diferentes tipos de apoio, bolsas ou financiamentos indicam uma possível relação de causa e efeito atuando sobre os índices de evasão. A variável inadimplência permite identificar que a condição financeira tem influência no momento da evasão, pois o percentual de evadidos é superior entre quem esteve, em algum momento do curso, em condição de inadimplência. $\bigcirc$ fato de os alunos receberem qualquer tipo de ajuda financeira indica que seu potencial de evasão é menor, se comparado com aqueles que não recebem nenhum tipo de ajuda financeira. Da mesma forma, observa-se para quem tem algum tipo de ajuda - por exemplo, mediante bolsa filantropia, financiamento, Fies, amparo social e ProUni -, sua chance de se evadir diminui em comparação com aqueles que não possuem algum tipo de apoio financeiro.

Outras variáveis também pesquisadas indicam que a evasão não se diferencia, significativamente, quanto a algumas classificações, como, por exemplo,o gênero. $O$ tipo de escola, regularmente frequentada no ensino médio, mostrou que, enquanto $64,51 \%$ dos ingressantes oriundos de escolas estaduais se evadem da Universidade, 53,07\% dos alunos que cursaram escola privada se evadem. 
No questionário do aluno ingressante por meio do processo vestibular, há a indagação sobre qual o principal motivo de escolha do curso. $\bigcirc$ motivo predominantemente assinalado é o que relata a adequação da escolha com as aptidões pessoais do aluno, mas é a alternativa indicação por testes vocacionais $(51,52 \%)$ e prestígio social da profissão $(51,43 \%)$ que apresentam as menores taxas de evasão. $\bigcirc$ percentual maior está na opção mercado de trabalho $(68,26 \%)$. Nesse caso, a escolha do curso se dá não por aptidão ou preferência, mas por oportunidade.

Um aspecto primordial a ser considerado é com relação ao fato de que alunos com três semestres consecutivos sem matrícula tem uma chance de se evadir muito superior $(74,71 \%)$ àqueles que não ficam nessa condição $(8,46 \%)$. Esse aspecto destaca essa variável, que já havia sido relevada no estudo anterior (2008).

A seguir, têm-se os procedimentos básicos de aplicação de uma análise multivariada de regressão logística. A avaliação da qualidade do ajuste da Regressão Logística passa pela análise de uma série de testes e indicadores que contribuem para que se possa decidir a esse respeito. A seguir,apresentam-se esses testes e indicadores para que seja feita uma análise conjunta de seus resultados. Não existe uma orientação sobre qual é o mais importante, pois eles avaliam situações e concluem com base em distintas visões. Por isso, é fundamental avaliar todos conjuntamente e não esquecer que uma amostra bastante expressiva possibilita maior sensibilidade dos testes aplicados, como é o caso desse estudo.

Uma das principais medidas de avaliação da Regressão Logística é o Log Likelihood Value (-2LL). Esse indicador mostra a capacidade de o modelo estimar a probabilidade associada à ocorrência de determinado evento. No estudo em questão, o evento está associado à previsão de evasão para um determinado discente. Em termos de significado, quanto menor o valor desse indicador, maior o poder preditivo (definir um aluno como sendo evadido quando ele realmente é, e vice-versa) do modelo.

teste Cox \& Snell R-Squared serve para comparar o desempenho de modelos concorrentes. Entre duas equações logísticas igualmente válidas, deve-se preferir a que apresente o Cox \& Snell R-Squared mais elevado. Esse indicador baseia-se no Log Likelihood Value e quanto maior o seu valor, melhor a qualidade do ajuste. Sua finalidade é a mesma do Cox \& Snell R-Squared, 
A evasão nos cursos de graduação em uma instituição de ensino superior privada

porém assume a "ideia" do coeficiente de explicação do ajuste pela regressão linear múltipla (de $\mathrm{O}$ a 1). Analisando-se os resultados obtidos por meio do software,todos os indicadores apresentados indicam que o modelo pode ser aplicado.

O teste Hosmer e Lemes how é obtido mediante um teste Quiquadrado, que consiste em dividir o número de observações em 10 classes e, em seguida, comparar as frequências preditas pelo modelo com as observadas no estudo de coorte. Em função disso, a finalidade desse teste é verificar se existem diferenças significativas entre as classificações realizadas pelo modelo e a realidade observada. Como o método possui várias etapas, o passo 9 foi o escolhido, uma vez que revelou melhores resultados.

Com determinado nível de significância, busca-se aceitar a hipótese de que não existem diferenças entre os valores preditos e observados. Caso exista diferença entre os valores, então o modelo não seria capaz de produzir estimativas e classificações muito confiáveis. Com o resultado desse indicador,o modelo seria apropriado, visto que não mostra diferença entre o valor observado e o estimado.

A definição sobre o modelo final de regressão logística passa pela análise da sua qualidade, realizada anteriormente, e da composição do modelo com o melhor conjunto possível de variáveis. $\bigcirc$ modelo inicialmente proposto apresentou um conjunto de 34 variáveis independentes.

Os resultados iniciais apresentam o resumo dos dados que foram efetivamente processados no modelo logístico. De um total de 5.331 casos, $2.150(40,3 \%)$ foram utilizados, sendo que 3.181 casos foram eliminados por não terem informação em, pelo menos, uma variável. Aparentemente, esse resultado elimina uma quantidade muito significativa de informações. Isso aconteceu na variável média no vestibular, que não estava disponível para alunos por outras formas de ingresso. Numa primeira tentativa, foi retirada essa variável do modelo, e a quantidade de dados incluídos aumentou significativamente, porém, quando analisada a capacidade preditiva do modelo, principal indicador de eficiência de uma regressão, ela piora com a retirada da variável média de desempenho no vestibular.

Esse fato corrobora a importância dessa variável na capacidade de o modelo fazer previsões sobre a ocorrência da evasão. Com isso, a opção foi manter a variável no modelo. Ao final, verifica-se que a variável não aparece 
na composição do modelo, mas garantiu uma melhor predição dos resultados. Assim, entende-se que o modelo confunde duas ou mais variáveis e escolhe, apenas, uma para compor o modelo de previsão.

Os resultados apresentados indicam a composição final do modelo, assim como as respectivas variáveis que o integram.

\section{Tabela 1}

Modelo final de regressão logística

\begin{tabular}{c|c|c|c|c}
\hline Variáveis & $B$ & $\operatorname{Exp}(\mathrm{B})$ & \multicolumn{2}{|c}{$95 \%$ C.I. for $\operatorname{EXP}(\mathrm{B})$} \\
\cline { 4 - 5 } & & & Lower & Upper \\
\hline Área & & & & \\
área(1) & $-0,217$ & 0,805 & 0,519 & 1,248 \\
área(2) & 0,176 & 1,193 & 0,819 & 1,737 \\
área(3) & 0,321 & 1,378 & 0,967 & 1,964 \\
área(4) & $-0,610$ & 0,543 & 0,241 & 1,222 \\
área(5) & $-0,068$ & 0,935 & 0,613 & 1,426 \\
Idade & $-0,037$ & 0,963 & 0,940 & 0,988 \\
Aprovadas & $-2,034$ & 0,131 & 0,096 & 0,177 \\
transferência_interna(1) & 0,010 & 1,010 & 1,005 & 1,016 \\
créditos_concluidos & 0,010 & 1,010 & 1,004 & 1,015 \\
inadimplente(1) & 0,352 & 1,422 & 1,083 & 1,868 \\
três_semestres(1) & 2,800 & 16,438 & 11,102 & 24,339 \\
ajuda_licenciatura(1) & 0,756 & 2,129 & 1,257 & 3,604 \\
Constant & $-0,734$ & 0,704 & 0,528 & 0,939 \\
\hline
\end{tabular}

Fonte | Software estatístico

Na Tabela 1, a regressão logística mostra que as variáveis que compõem o modelo são: área de conhecimento; a idade do aluno; o fato de ter ou não realizado alguma transferência interna; o percentual de aprovação nas atividades acadêmicas; a quantidade de créditos já concluídos; o fato de estar inadimplente em algum período; e o fato de estar, há três semestres, sem realizar matrícula. Nessa tabela, aparecem os valores de Exp (B), o que indica o quanto aumenta ou diminui a probabilidade de um aluno se evadir, visto que ocorre uma alteração nessa variável e as demais permanecem iguais. Destaca-se o resultado obtido pelo fato de o aluno estar três semestres consecutivos sem matrícula, onde $\operatorname{Exp}(B)$ é igual a 16,438, ou seja, um aluno 
que chega a essa situação tem 1.543,8\% de chance maior que os demais, de se evadir do curso. Nesse caso, convém atuar junto aos alunos em início de curso, visto que, também, as taxas de evasão, calculadas pelo indicador Universidade, mostram que, nos primeiros semestres, é quando existe a maior evasão de alunos.

A partir do conjunto de dados estabelecido para se ajustar um modelo de regressão logística, seguem algumas considerações importantes. Em primeiro lugar, as conclusões apresentadas pelo modelo dependem muito do conjunto de variáveis que se optou por incluir inicialmente. Ao final das etapas de ajuste, o modelo de regressão logística pode realizar previsão com base em probabilidade de chance de acerto conhecida.

$\bigcirc$ modelo logístico final proposto é: $Y=-0,734-0,217$ área (1) $+0,176$ área (2) +0,32 1 área (3) -0,61 área (4) -0,068 área (5)-0,037 idade -2,034 transferência_interna $(1)+0,01$ aprovadas $+0,01$ créditos_concluidos $+0,352$ inadimplente $(1)+2,8$ três_semestres $+0,756$ ajuda_licenciatura (1)

Onde:

Y é a variável resposta (sim ou não) o aluno se evade

$-0,734$ é a constante do modelo

área (1) quando o curso for da área de Ciências da Comunicação

(demais igual a zero)

área (2) quando o curso for da área de Ciências Econômicas (demais igual a zero)

área (3) quando o curso for da área de Ciências Exatas (demais igual a zero)

área (4) quando o curso for da área de Ciências Humanas (demais igual a zero)

área (5) quando o curso for da área de Ciências Jurídicas (demais igual a zero)

área quando o curso for da área de Ciências da Saúde (zero para todas)

idade é a idade do aluno no momento de ingresso no curso

transferência_interna é quando o aluno realizou transferência interna (1) ou não (0)

aprovadas é o percentual de disciplinas aprovadas no período

créditos_concluidos é a quantidade de créditos já concluídos pelo aluno inadimplente ficou inadimplente (1) ou quando não ficou (0)

três_semestres ficou três semestres consecutivos sem matrícula sim (1) e não (0)

ajuda_licenciatura é quando o aluno recebe a ajuda (1) ou não (0)

Dessa forma, a probabilidade de o aluno se evadir do curso de graduação acaba sendo medida não pela fórmula de ajuste, pois ela é construída a 
partir de um modelo logit (logarítmico natural). Mas a probabilidade pode ser obtida da seguinte forma:

$$
P(\text { evadir })=\frac{1}{1+e^{-y}}
$$

Nesta expressão, o Y representa a equação de regressão logística. Após a substituição dos valores das variáveis, é possível determinar a probabilidade de evasão.Como a variável resposta é dicotômica, então o modelo estabelece que, se a probabilidade calculada for superior a 0,50 , o aluno se evade; caso contrário, não.

Como exemplo, um aluno com as seguintes características:Ingressou em um curso da área 1 - área $(1)=1$ zero para os demais; é de um curso da área de Ciências Exatas (área (3) = 1 e zero para as demais); ingressou no curso com 30 anos; já realizou transferência de curso - transferência_interna = 1 ; foi aprovado em 50\% das disciplinas que se matriculou - aprovadas = 50; já concluiu 16 créditos do seu curso - créditos_concluidos = 16; esteve inadimplente durante um período - inadimplente $=1$; ficou três semestres consecutivos sem matrícula - três_semestres $=1$ e recebe bolsa licenciatura - ajuda_licenciatura $=1$, qual seria a sua probabilidade de se evadir?

$$
P(\text { evadir })=\frac{1}{1+e^{-(-0,734+0,321(1)-0,037(30)-2,034(1)+0,01(50)+0,01(16)+0,352(1)+2,8(1)+0,756(1))}}
$$

$$
P(\text { evadir })=\frac{1}{1+e^{-0,473}}=\frac{1}{1+0,6231}=\frac{1}{1,6231}=0,6161
$$

Com base nesse resultado, o aluno fica caracterizado como possível evadido (pois a probabilidade é maior que 0,50), tendo 61,61\% de chance de se evadir. De modo geral, é possível resumir o modelo de evasão de 2011 pela Figura 2. 


\section{Figura 2}

\section{Principais variáveis que interferem na evasão ins- titucional da Universidade em 2011}

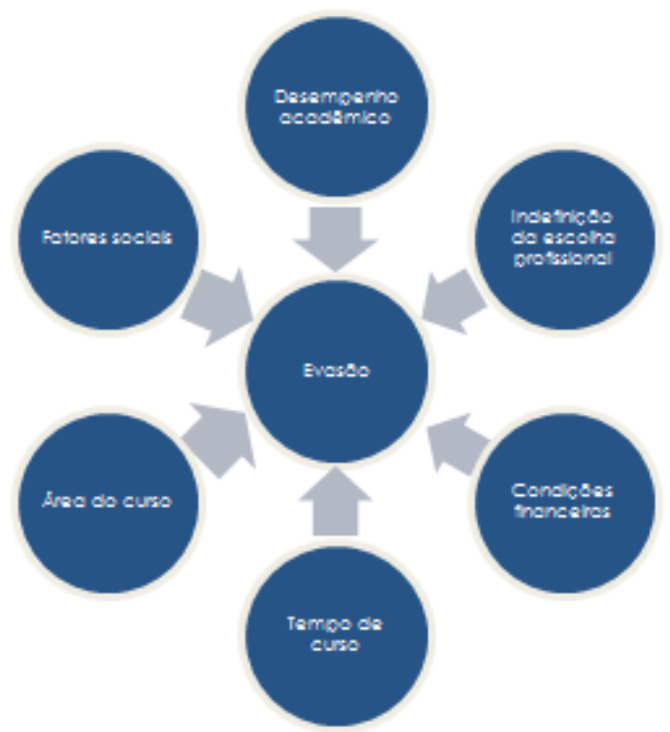

Fonte | Estudo realizado pelos autores em 2011

Os grandes grupos que aparecem na Figura 2 são representados pelas variáveis incluídas no modelo de regressão. O que diferencia essa representação da obtida pelo estudo de 2008 é a inclusão dos fatores sociais.

Os passos adotados até a conclusão final do modelo de regressão logística avaliaram as contribuições das variáveis a partir de um conjunto de indicadores de qualidade de ajuste. Além desse fato, coube, também, ao pesquisador avaliar os resultados obtidos e buscar novos caminhos para a solução dos problemas encontrados.

modelo final de ajuste incluiu variáveis oriundas das mais diversas áreas, tanto variáveis de escolha por curso e desempenho nas atividades acadêmicas quanto variáveis de natureza bastante diferenciada. Esse fato alerta para o indício de que existe uma complexidade de fatores que interferem no fenômeno da evasão. Esses fatores podem ser muito diversos de um aluno para 
outro. Enquanto para alguns a indecisão pela escolha passa a ter importância fundamental, para outros as lacunas decorrentes de sua formação anterior dificultam sua trajetória no curso, entre outros fatores.

modelo final apresenta, a partir da composição de um conjunto de variáveis, a probabilidade de ocorrência de um aluno se evadir da instituição. Essa probabilidade, quando inferior a 50\%, é um indicativo de que talvez o aluno não vá se evadir (variável resposta); por outro lado, quando superior a esse valor, mostra indícios de que ele pode se evadir. Considerações sobre a variável resposta não são conclusivas, pois trabalham com probabilidades e não com certezas. Modificações no perfil do aluno alteram a sua probabilidade de evasão.

A comparação dos resultados obtidos, no estudo de 2008, com o realizado em 2011 reitera aspectos relevantes na compreensão da evasão. $\bigcirc$ principal aspecto a ser avaliado foi com relação ao indicador de evasão, que, em 2008, (com base nos ingressantes em 2003) era de 53,79\% e apresentou uma tendência de crescimento muito significativa, passando em 2011 (com base em 2006) a ser de 56,67\%. Nem os alunos ingressantes em 2003 e os ingressantes em 2006 foram alvo de alguma ação institucional de combate à evasão, efetivada a partir do primeiro estudo, impactando os ingressantes a partir de 2008. Com isso, verifica-se que a tendência da evasão institucional era de crescimento.

Um aspecto que diferencia o estudo de 2008 com o realizado em 2011 foi que, na primeira edição, houve, além do estudo quantitativo, uma coleta de dados qualitativa, incluindo, assim, aspectos mais subjetivos que interferem na construção do processo de evasão institucional. Na configuração da evasão do estudo realizado em 2008 (Figura 1), destacam-se as variáveis de desempenho acadêmico, indefinição da escolha profissional, condições financeiras, tempo de curso e área a que o curso de graduação está vinculado. Essas variáveis se repetem no modelo de evasão institucional de 2011 , demonstrando que a realidade não se alterou muito no panorama da evasão institucional. A diferença, em 2011 , é que passa a ser incluída uma variável de cunho social. 


\section{Conclusões}

A partir da análise descritiva dos resultados, percebe-se que algumas variáveis podem identificar uma maior ou menor propensão a um aluno se evadir da instituição. Algumas dessas variáveis estão relacionadas a fatores sociais, econômicos, de desempenho acadêmico e de escolha profissional, entre outras. A construção dessa representação tem como base a análise bivariada dos dados.

Figura 3

Resumo das variáveis de maior risco de evasão

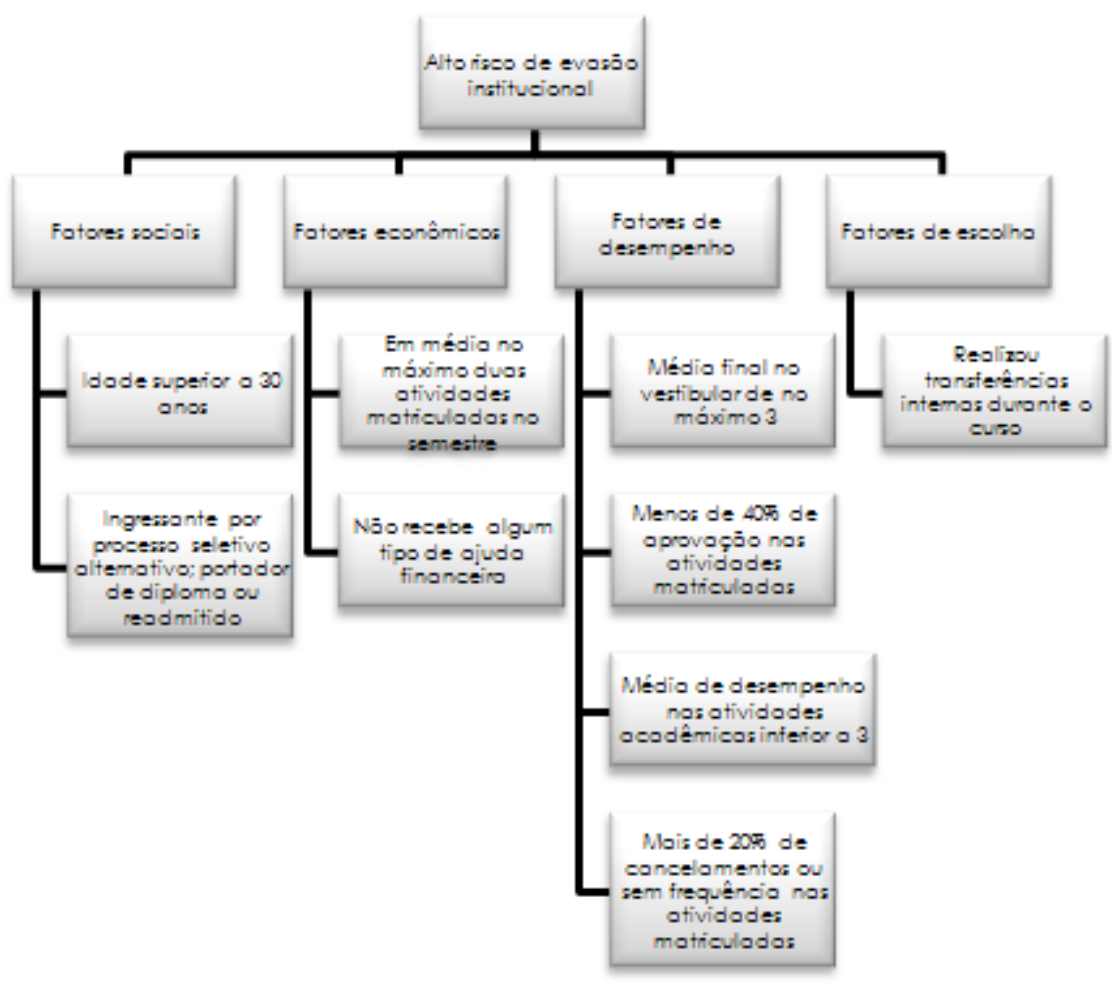

Fonte | Estudo realizado pelos autores em 2011 
As questões apresentadas nesse resumo foram aquelas em que a diferença entre as categorias de resposta das variáveis apresentaram muita discrepância, indicando a necessidade de um acompanhamento mais individual, como forma de ação para a prevenção da evasão institucional. Não está, no modelo, a variável três semestres consecutivos sem matrícula, ainda que seja muito representativa no modelo. Esse fato ocorre porque essa variável pode estar inserida em todos os fatores constantes na representação.

Com relação aos fatores sociais, identificaram-se duas variáveis: idade superior a 30 anos e ingresso por processo seletivo alternativo, portador de diploma e readmitido. Com relação à variável idade, em alguns casos, os ingressantes são oriundos de programas do tipo Educação para Jovens e Adultos (EJA), supletivos ou mesmo concluíram o ensino médio há muito tempo. Em qualquer dessas circunstâncias, a situação do aluno, em relação ao preparo para um curso superior, é desvantajosa pelo tempo de afastamento e pelas perspectivas de futuro em relação à conclusão de um curso em nível superior. Os ingressantes por diploma ou processo seletivo alternativo tendem a ter mais idade, caindo alguns na situação apresentada acima.

As variáveis que compõem o fator econômico foram identificadas como em média no máximo duas atividades matriculadas no semestre e não receber algum tipo de ajuda financeira. De todas as ajudas pesquisadas, apenas a bolsa licenciatura não fez diferença na evasão da instituição porque, provavelmente, os ingressantes em geral de classes mais desfavorecidas já sinalizaram dificuldades em arcar com o valor da mensalidade com o desconto da bolsa. Nos demais casos, os que tinham algum tipo de auxílio apresentavam taxas de evasão menores dos que não tinham.

As questões que envolvem o desempenho acadêmico do aluno, ao longo de sua permanência anterior à evasão, foram identificadas como sendo: média no vestibular de, no máximo, três; menos de 40\% de aprovação nas atividades cursadas; média de desempenho nas atividades acadêmicas inferior a três e mais de $20 \%$ de cancelamentos ou sem frequências nas atividades acadêmicas. Esses dois últimos fatores podem não, necessariamente, estar vinculados a problemas acadêmicos, como cancelamento por problema financeiro ou de outra natureza, principalmente quando ocorrem no início do semestre. Podem estar associados a situações de fracasso, alunos que desistem pela dificuldade de serem aprovados na disciplina, por falta de maturidade como universitário, que, por sua vez, podem estar implicados com aspectos 
como relação professor/aluno, metodologias de ensino e aprendizagem e avaliação, entre outros.

Com relação a fatores de desempenho, verifica-seque, nas questões de ingresso com média de, no máximo, três e média de desempenho nas atividades inferior a três, a relação média e taxa de evasão é inversamente proporcional, ou seja, à medida que aumenta a média, a tendência, nos dois casos,é de que diminua a propensão de ocorrer a evasão institucional.

No fator de escolha profissional, a variável "realizou transferências internas durante o período pesquisado" indica que o fato de o aluno ficar se transferindo de curso já é um indicativo de indefinição da escolha profissional ou valor social da profissão e contribui para a evasão. A esse fato se soma a informação de que a escolha do curso, por meio de testes vocacionais, comprova que a evasão é inferior, ligeiramente, às demais opções de escolha do curso a seguir.

Com relação ao ajuste da Regressão Logística, as considerações sobre as variáveis, apresentadas na análise bivariada de forma descritiva, passam a ter outro entendimento. Quando uma variável possui relevância na evasão institucional e é identificada de forma bivariada direta, isto é, isolando-a das demais, não se pode identificar a interação entre elas. Por isso, ao se analisar as variáveis por meio de um modelo multivariado, as interações revelam como a presença de uma ou mais variáveis explica o fenômeno da evasão.

Em alguns casos, as variáveis destacadas anteriormente não aparecem no modelo logístico por serem concomitantes; por exemplo, se a média nas disciplinas é baixa e existem muitas reprovações, isso significa a mesma coisa para o modelo e ele não considera as duas variáveis, mas, apenas, uma. Por outro lado, uma variável pode aparecer no modelo, mas não ter sido destacada como representativa, fato que pode acontecer quando essa nova variável se encontra com a presença das demais que eram representativas; por exemplo, o gênero pode não ser representativo no fenômeno da evasão, mas, se alunos do sexo masculino têm menor desempenho, o gênero passa a ser relevante.

Utilizando a análise multivariada, as variáveis presentes no modelo não se diferenciaram muito da natureza das que constaram no modelo de 2008. Em 2011 , aparece um indicador de ordem social, que não estava presente no modelo anterior. As variáveis do modelo final de regressão não são as 
mesmas destacadas na análise bivariada dos dados, como também explicado acima.

Um ponto em destaque é que os dois estudos, realizados em momentos diferentes, apontam, fortemente, para a variável três semestres consecutivos sem matrícula como o principal indicador de evasão institucional. É fundamental, além do acompanhamento das demais variáveis em destaque no estudo, um conjunto de ações direcionado aos alunos em início de curso, pois, nessa etapa, é que surgem os primeiros sinais de dificuldade de acompanhamento das exigências das atividades acadêmicas, de pagamento de mensalidades, de incerteza quanto à escolha profissional, entre outros fatores que tendem a desencadear a evasão.

Recomenda-se que a evasão seja incluída como um indicador de gestão das instituições de educação superior na medida em que estudos de natureza qualitativa e quantitativa, o monitoramento e acompanhamento de seus índices, ao planejamento, execução e avaliação de ações imprimem novos olhares e perspectivas de docentes e gestores visando à garantia da permanência e conclusão dos estudantes nos cursos de graduação.

\section{Referências}

ADACHI, Ana Amélia Chaves Teixeira. Evasão e evadidos nos cursos de graduação da Universidade Federal de Minas Gerais. 2009. 21 4f. Dissertação (Mestrado em Educação) - Programa de Pós-Graduação em Educação, Universidade Federal de Minas Gerais, Belo Horizonte, 2009.

ANDRIOLA, Wagner. Fatores associados à evasão discente na Universidade Federal do Ceará (UFC) de acordo com as opiniões de docentes e de coordenadores de cursos. Revista Iberoamericana sobre Calidad, Eficacia y Cambio em Educación - REICE, Madrid (Espanha), v. 7, n. 4, p. 342-356, trimestral, 2009. Disponível em: http://www.redalyc. org/pdf/551/55114094018.pdf. Acesso em: 30 ago. 2014.

AMARAL, João Batista do. Evasão discente no ensino superior: estudo de caso no Instituto Federal de Educação, Ciência e Tecnologia do Ceará (Campus Sobral). 2013. $48 f$. Dissertação (Mestrado Profissional em Políticas Públicas e Gestão da Educação Superior) Programa de Pós-Graduação-Superintendência de Recursos Humanos, Universidade Federal do Ceará, Fortaleza, 2013. 
A evasão nos cursos de graduação em uma instituição de ensino superior privada

BAGGI, Cristiane Aparecida dos Santos. Evasão e avaliação institucional: uma discussão bibliográfica. 2010. 81 f. Dissertação (Mestrado em Educação) - Programa de Pós-Graduação em Educação, Pontifícia Universidade Católica de Campinas, Campinas, 2010.

BARDAGI, Marúcia Patta. Evasão e comportamento vocacional de universitários: estudos sobre o desenvolvimento de carreias na graduação. 2007. 242f. Tese (Doutorado em Psicologia) - Programa de Pós-Graduação em Psicologia. Universidade Federal do Rio Grande do Sul, Porto Alegre, 2007.

BIAZUS, Cleber Augusto. Sistema de fatores que influenciam o aluno a evadir-se dos cursos de graduação na UFSM e na UFSC: um estudo no curso de Ciências Contábeis. 2004. 203f. Tese (Doutorado em Engenharia de Produção) - Programa de Pós-Graduação em Engenharia de Produção. Universidade Federal de Santa Catarina, Florianópolis, 2004.

BRASIL. Lei n 9.394, de 20 de dezembro de 1996. Estabelece as Diretrizes e Bases da Educação Nacional. Diário Oficial [da] República Federativa do Brasil, Poder Executivo, Brasilia, DF, 23 dez. 1996, seção 1, p. 12. Disponível em: http://www.planalto.gov.br/ ccivil_03/leis/L9394.htm. Acesso em: 15 out. 2011.

Instituto Nacional de Estudos e Pesquisas Educacionais Anísio Teixeira. Ministério

105 da Educação. Censo da Educação Superior 2010, 2011, 2012. Brasília. Disponível em: http://download.inep.gov.br/educacao_superior/documens/2010/censo_2010.pdf. Acesso em: 2 ago. 2014.

Lei ${ }^{\circ}$ 13.005, de 25 de junho de 2014. Aprova o Plano Nacional de Educação-PNE e dá outras providências. Disponível em: http://www. planalto.gov.br/CCIVIL_03/_Ato201 1 2014/2014/Lei/L13005.htm. Acesso em: 22 abr. 2014.

CORRAR, Luiz; PAULO, Edílson; DIAS FILHO, José Maria. Análise multivariada para os cursos de administração, ciências contábeis e economia. São Paulo: Atlas, 2007.

DIAS SOBRINHO, José. Dilemas da educação superior no mundo globalizado: sociedade do conhecimento ou economia do conhecimento?. São Paulo: Casa do Psicólogo Livraria e Editora Ltda, 2005.

BRITO, Márcia Regina Ferreira de. La educación superior en Brasil: principales tendencias y desafíos. Revista da Avaliação da Educação Superior, Sorocaba, v. 13, n. 2, p. 487-507, jul. 2008.

Democratização, qualidade e crise da educação superior:faces da exclusão e limites da inclusão. Educação \& Sociedade, Campinas, v. 31 , n. 1 13, p. 1223-1245, dez. 
2010. Disponível em: http://www.scielo.br/scielo.php?acript=sci_arttex\&pid=S0101$-73302010000400010 \& \mathrm{ng}=$ pt\&nrm=iso. Acesso em: 24 nov. 2011.

DOURADO, Luiz Fernandes. Reforma do Estado e as políticas para a educação superior nos anos 90. Educação \& Sociedade, Campinas, v. 23, n. 80, p. 234-252, set./dez. 2002.

Políticas e gestão da educação superior no Brasil: múltiplas regulações e controle.

Revista Brasileira de Política e Administração da Educação, Rio de Janeiro, v. 27, n. 1, p. 53-65, jan./abr. 2011.

FIALHO, Mônica Maria Lima. Evasão no ensino superior privado:um estudo de caso na Universidade Santo Agostinho. 2008. 57f. Dissertação (Mestrado Profissional) - Programa de Pós-Graduação em Economia, Universidade Federal do Ceará, Fortaleza, 2008.

HAIR, Joseph; ANDERSON, Rolph; TATHAM, Ronald; BLACK, William. Análise multivariada de dados. 5. ed. Porto Alegre: Bookman, 2005.

HILL, Carter; GRIFFITHS, William; JUDGE, George. Econometria. São Paulo. Saraiva, 1999.

MALHOTRA, Naresh. Pesquisa de marketing:uma orientação aplicada. 3. ed. Porto Alegre: Bookman, 2001.

MANCEBO, Deise. Reforma da educação superior: o debate sobre a igualdade no acesso. In: BITTAR, Mariluce; OLIVEIRA, João Ferreira de; MOROSINI, Marília (Org.). Educação superior no Brasil - 10 anos pós-LDB. Brasília: Instituto Nacional de Estudos e Pesquisas Educacionais Anísio Teixeira, 2008.

MARTINS, Cleidis Beatriz Nogueira. Evasão de alunos nos cursos de graduação em uma instituição de ensino superior. 2007. 116 f. Dissertação (Mestrado em Administração) - Programa de Pós-Graduação em Administração, Fundação Dr. Pedro Leopoldo, Pedro Leopoldo (Minas Gerais), 2007.

MATIAS, Irlene dos Santos. Centro Federal de Educação Tecnológica do Amazonas: uma reflexão sobre as condições de ingresso, permanência e evasão. 2003. 90f. Dissertação (Mestrado em Educação) - Programa de Pós-Graduação em Educação e Trabalho, Universidade Federal de Santa Catarina, Florianópolis, 2003.

PALÁCIO, Paula da Paz. Políticas de acesso e permanência do estudante da Universidade Federal do Ceará (UFC). $2012.123 f$. Dissertação (Mestrado em Políticas Públicas e Gestão da Educação Superior) - Programa de Pós-Graduação em Políticas Públicas e Gestão da Educação Superior, Universidade Federal do Ceará, Fortaleza, 2012. 
PEREIRA, Fernanda Cristina Barbosa. Determinantes da evasão de alunos e os custos ocultos para as instituições de ensino superior: uma aplicação na universidade do extremo sul catarinense. 2003. 173f. Tese (Doutorado em Engenharia da Produção) - Programa de Pós-Graduação em Engenharia de Produção, Universidade Federal de Santa Catarina, Florianópolis, 2003.

PEREIRA JÚNIOR, Edgar. Compromisso com o graduar-se, com a instituição e com o curso: estrutura fatorial e relação com a evasão. 2012. 41 ff. Dissertação (Mestrado em Educação) - Programa de Pós-Graduação em Educação, Universidade Estadual de Campinas, Campinas, 2012.

PERONI, Vera Maria Vidal. Política educacional e papel do Estado. São Paulo: Xamã, 2003.

PERONI, Vera Maria Vidal (Org.). Redefinições das Fronteiras entre o público e o privado: implicações para a democratização da educação. Brasília: Liber Livro, 2013.

RIBAS, José Roberto; VIEIRA, Paulo Roberto da Costa. Análise multivariada com o uso do SPSS. Rio de Janeiro: Ciência Moderna, 2011.

SILVA, Marilene de Almeida Viana Reid. A evasão na UENF: uma análise dos cursos de licenciatura 2003-2007. 2009. 193f. Dissertação (Mestrado em Políticas Sociais) - Programa de Pós-Graduação em Políticas Sociais, Universidade Estadual do Norte Fluminense, Rio de Janeiro, 2009

SILVA FILHO, Roberto Leal Lobo; MOTEJUNAS, Paulo Roberto; HIPÓlITO, Oscar; LOBO, Maria Beatriz de Carvalho Melo. A evasão no ensino superior brasileiro. Cadernos de Pesquisa, São Paulo, v. 37, n. 132, p. 641-659, set./dez. 2007.

TEIXEIRA, Levi Lopes Teixeira. O uso de técnicas de estatística multivariada no prognóstico de desistência de alunos em IES privadas: um estudo de caso na cidade de Foz do Iguaçu-PR. 2006. 79f. Dissertação (Mestrado em Ciências) - Programa de Pós-Graduação em Métodos Numéricos em Engenharia, Universidade Federal do Paraná, Curitiba, 2006.

VELOSO, Tereza Christina; ALMEIDA, Edson Pacheco de. Evasão nos Cursos de Graduação da Universidade Federal de Mato Grosso, campus universitário de Cuiabá - um processo de exclusão. Série-Estudos, Campo Grande, n. 13, p. 133-148, jan./jun. 2002. Disponível em: http://www.serie-estudos.ucdb.br/index.php/serie-estudos/article/view/564/453. Acesso em: 1 ago. 2014. 
Profa. Dra. Rosangela Fritsch

Universidade do Vale do Rio dos Sinos | São Leopoldo Unidade Acadêmica de Pesquisa e Pós-Graduação

Programa de Pós-Graduação em Educação

Programa de Pós-Graduação em Gestão Educacional

Grupo de PesquisaHistória, Política e Gestão da Escola Básica Rede Ibero-Americana de Estudos sobre Educação Profissional e Evasão Escolar | RIMEPES | UFMG E-mail | rosangelał@unisinos.br

Doutoranda Cleonice Silveira da Rocha Universidade do Vale do Rio dos Sinos | São Leopoldo Programa de Pós-Graduação em Educação Grupo de Pesquisa História, Política e Gestão da Escola Básica E-mail | nice@unisinos.br

Doutorando Ricardo Ferreira Vitelli Universidade do Vale do Rio dos Sinos | São Leopoldo Programa de Pós-Graduação em Educação Grupo de Pesquisa História, Política e Gestão da Escola Básica E-mail | vitelli@unisinos.br

Recebido 13 out. 2014 Aceito 11 dez. 2014 